\title{
Osteoporosis medication prescribing in British Columbia and Ontario: impact of public drug coverage
}

\author{
S. M. Cadarette • G. Carney • D. Baek • N. Gunraj • \\ J. M. Paterson • C. R. Dormuth
}

Received: 27 June 2011 / Accepted: 11 August 2011 /Published online: 8 September 2011

(C) The Author(s) 2011. This article is published with open access at Springerlink.com

\begin{abstract}
Summary We compared the patterns of osteoporosis medication prescribing between two provinces in Canada with different public drug coverage policies. Oral bisphosphonates were the primary drugs used, yet access to the secondgeneration oral bisphosphonates (alendronate, risedronate) was limited in one region. Implications of differential access to oral bisphosphonates warrants further study.

Introduction Approved therapies for treating osteoporosis in Canada include bisphosphonates, calcitonin, denosumab, raloxifene, and teriparatide. However, significant variation in access to these medications through public drug coverage exists across Canada. We sought to compare patterns of
\end{abstract}

\section{S. M. Cadarette $(\bowtie) \cdot$ D. Baek}

Leslie Dan Faculty of Pharmacy, University of Toronto,

144 College Street,

Toronto M5S 3M2 ON, Canada

e-mail: s.cadarette@utoronto.ca

S. M. Cadarette $\cdot$ N. Gunraj $\cdot$ J. M. Paterson

Institute for Clinical Evaluative Sciences,

Toronto, ON, Canada

G. Carney $\cdot$ C. R. Dormuth

Therapeutics Initiative, University of British Columbia,

Victoria, BC, Canada

\section{J. M. Paterson}

Department of Family Medicine, McMaster University,

Hamilton, ON, Canada

\section{J. M. Paterson}

Centre for Evaluation of Medicines, St. Joseph's Healthcare,

Hamilton, ON, Canada

\section{J. M. Paterson}

Department of Health Policy, Management and Evaluation, University of Toronto,

Toronto, ON, Canada osteoporosis medication prescribing between British Columbia (BC) and Ontario.

Methods Using dispensing data from BC (PharmaNet) and Ontario (Ontario Drug Benefits), we identified all new users of osteoporosis medications aged 66 or more years from $1995 / 1996$ to $2008 / 2009$. We summarized the number of new users by fiscal year, sex, and index drug for each province. $\mathrm{BC}$ data were also stratified by whether drugs were dispensed within or outside public PharmaCare.

Results We identified 578,254 ( $n=122,653$ BC) eligible new users. Overall patterns were similar between provinces: (1) most patients received an oral bisphosphonate (93\% in BC and 99\% in Ontario); (2) etidronate prescribing declined after $2001 / 2002$, reaching a low of $41 \%$ in BC and $10 \%$ in Ontario in 2008/2009; and (3) the proportion of males treated increased over time, from $7 \%$ in $1996 / 1997$ to $25 \%$ in $2008 /$ 2009. However, we note major differences within versus outside the BC PharmaCare system. In particular, $<2 \%$ of drugs dispensed within PharmaCare compared to $79 \%$ of drugs dispensed outside PharmaCare were for a secondgeneration bisphosphonate (alendronate or risedronate).

Conclusions Oral bisphosphonates are the primary drugs used to treat osteoporosis in Canada. Prescribing practices changed over time as newer medications came to market, yet access to second-generation bisphosphonates through BC PharmaCare was limited. Implications of differential access to oral bisphosphonates warrants further study.

Keywords Drug policy · Osteoporosis · Pharmacotherapy

\section{Introduction}

Approved therapies for treating osteoporosis in Canada include bisphosphonates (alendronate, etidronate, risedro- 
nate, and zoledronic acid), calcitonin, denosumab, raloxifene, and teriparatide [1]. Each drug is effective in reducing vertebral fracture risk; however, only selected bisphosphonates (alendronate, risedronate, and zoledronic acid), denosumab, and teriparatide have demonstrated significant reductions in nonvertebral fracture risk compared to placebo $[2,3]$. Consequently, Canadian osteoporosis practice guidelines recommend etidronate, calcitonin, and raloxifene in a list of second-line options [1]. In contrast to practice guidelines, many publicly funded drug plans across Canada limit coverage for first-line therapies, yet provide unrestricted coverage for etidronate - a secondline therapy [4].

We used data from British Columbia (BC) and Ontario to compare osteoporosis treatment prescribing practices between provinces. In $\mathrm{BC}$, etidronate is the only osteoporosis medication listed under general benefits on its provincial drug formulary (PharmaCare). In Ontario, etidronate has been available without restriction since 1996, while alendronate and risedronate were initially subject to limited access criteria until 2007, when coverage broadened to include all three oral bisphosphonates without restriction. Other osteoporosis therapies are not listed on either public formulary or are only available under restricted conditions. We hypothesized that prescribing patterns would change over time as new osteoporosis therapies became available and as access through public drug plans broadened.

\section{Methods}

The PharmaNet database in $\mathrm{BC}$ includes all prescriptions dispensed in community pharmacies since April 1991. PharmaNet includes a field that differentiates between claims accepted for PharmaCare (BC public drug plan) coverage from those paid through private insurance or outof-pocket. In Ontario, only claims processed through the provincial public drug plan (Ontario Drug Benefits) were identifiable - these include drugs listed in the provincial formulary (Table 1) for all residents aged 65 or more years $[5,6]$.

Within each provincial pharmacy database, we identified the first dispensing date of an eligible osteoporosis medication (alendronate, cyclical etidronate, risedronate, raloxifene, nasal calcitonin, teriparatide, zoledronic acid). The first date an eligible osteoporosis medication was dispensed was considered the index date, and each person was identified only once. Given that Ontario drug data only include persons aged 65 or more years, we restricted inclusion to persons aged 66 or more years so that we could compare prescribing patterns between provinces among similarly aged patients and with at minimum 1 year of data to identify new users. We also excluded patients with more than one eligible osteoporosis medication dispensed at index, and those with use of a nonosteoporosis formulation or Paget's disease diagnosis within the 365 days prior to their index date.

The number of new users was examined by fiscal year, sex, and index drug within each province. $\mathrm{BC}$ data were also stratified by whether or not the index drug was accepted by PharmaCare. At the time of analysis, we had complete data from April 1995 to March 2009 in BC and Ontario.

\section{Results}

We identified 578,254 (122,653 $\mathrm{BC}$ and 455,601 Ontario) eligible new users (Fig. 1). Overall patterns of prescribing were similar between provinces: (1) most patients received an oral bisphosphonate $(93 \%$ in BC and 99\% in Ontario); (2) etidronate prescribing declined after $2001 / 2002$, reaching a low of $41 \%$ in BC and $10 \%$ in Ontario in 2008/2009; and (3) the proportion of males treated increased over time, from $7 \%$ in $1996 / 97$ to $25 \%$ in 2008/2009 (Fig. 2). Of interest, dispensing of new osteoporosis medications tended to occur a year earlier in BC than Ontario. For example, etidronate and daily alendronate both received notice of compliance in 1995 (Table 1) and were first dispensed in BC in 1995/1996 compared to 1996/1997 in Ontario. We also identified major differences in osteoporosis medications dispensed within versus outside the BC PharmaCare system (Fig. 3). In particular, $<2 \%$ of drugs dispensed within PharmaCare compared to $79 \%$ of drugs dispensed outside PharmaCare in $\mathrm{BC}$ were for a second-generation bisphosphonate (alendronate or risedronate).

The use of raloxifene, teriparatide, and zoledronic acid was low in both provinces. Raloxifene had a temporary increase in use at time of entry into the market around 2000 and then quickly declined as weekly bisphosphonates came to market in 2002. We document fewer than 20 teriparatide users and fewer than 210 users of zoledronic acid in BC and Ontario combined. We also identified little calcitonin use in Ontario (less than 1\% during the study period) yet note that calcitonin was dispensed to a similar number of patients since 2000/2001 in BC, with about 600 new patients treated with nasal calcitonin as their first osteoporosis medication annually.

\section{Discussion}

Prescribing practices of osteoporosis medication have changed over time in response to newly approved drugs 
Table 1 Notice of compliance dates for osteoporosis medications and current public formulary listing status in British Columbia and Ontario $[5,11]$

\begin{tabular}{|c|c|c|c|c|c|}
\hline Drug & Strength & Regimen & $\begin{array}{l}\text { Notice of } \\
\text { compliance }^{\mathrm{a}}\end{array}$ & $\begin{array}{l}\text { BC PharmaCare } \\
\text { listing status }\end{array}$ & $\begin{array}{l}\text { Ontario Drug Benefit } \\
\text { Formulary listing status }\end{array}$ \\
\hline \multicolumn{6}{|l|}{ Bisphosphonate } \\
\hline Etidronate and calcium & $400 / 500 \mathrm{mg}$ tab & $\begin{array}{l}14 \text { days oral etidronate } \\
\text { then } 76 \text { days oral calcium }\end{array}$ & 19 Jul 1995 & $\begin{array}{l}\text { General benefits } \\
\text { (since 1995) }\end{array}$ & $\begin{array}{l}\text { General benefits } \\
\text { (since 1996) }\end{array}$ \\
\hline Alendronate & $\begin{array}{l}10 \mathrm{mg} \text { tab } \\
70 \mathrm{mg} \text { tab }\end{array}$ & $\begin{array}{l}\text { Daily_oral } \\
\text { Weekly_oral }\end{array}$ & $\begin{array}{l}18 \text { Dec } 1995 \\
04 \text { Feb } 2002\end{array}$ & Limited coverage $^{\mathrm{b}}$ & $\begin{array}{l}\text { General benefits } \\
\text { (since January } \\
2007)^{\mathrm{c}}\end{array}$ \\
\hline \multirow[t]{3}{*}{ Risedronate } & $\begin{array}{l}5 \mathrm{mg} \text { tab } \\
35 \mathrm{mg} \text { tab }\end{array}$ & $\begin{array}{l}\text { Daily_oral } \\
\text { Weekly_oral }\end{array}$ & $\begin{array}{l}17 \text { Jul } 2000 \\
09 \text { Dec } 2002\end{array}$ & Limited coverage $^{\mathrm{b}}$ & $\begin{array}{l}\text { General benefits } \\
\text { (since June 2007) }^{c}\end{array}$ \\
\hline & $75 \mathrm{mg}$ tab & $\begin{array}{l}\text { Monthly-oral } \\
\text { ( } 2 \text { consecutive days })\end{array}$ & 17 Jul 2007 & Not listed & Not listed \\
\hline & $150 \mathrm{mg}$ tab & Monthly_oral & 24 Sep 2008 & Not listed & $\begin{array}{l}\text { General benefits } \\
\text { (since July 2010) }\end{array}$ \\
\hline $\begin{array}{l}\text { Zoledronic acid } \\
\text { Other }\end{array}$ & $5 \mathrm{mg} / 100 \mathrm{ml}$ & Annual infusion & 29 Oct 2007 & Not listed & Limited coverage ${ }^{\mathrm{d}}$ \\
\hline Calcitonin & $200 \mathrm{U} / \mathrm{spr}$ & Daily_nasal spray & 01 Sep 1999 & Not listed & Limited coverage ${ }^{\mathrm{e}}$ \\
\hline Denosumab & $60 \mathrm{mg} / \mathrm{ml}$ & Semi-annual injection & 06 Aug 2010 & Not listed & Not listed \\
\hline Raloxifene & $60 \mathrm{mg}$ tab & Daily_oral & 06 Nov 1998 & Limited coverage $\mathrm{e}^{\mathrm{f}}$ & Limited coverage $\mathrm{e}^{\mathrm{g}}$ \\
\hline Teriparatide & $250 \mu \mathrm{g} / \mathrm{ml}$ & Daily_subcutaneous injection & 03 Jun 2004 & Not listed & Not listed \\
\hline
\end{tabular}

General benefits covered without restriction, Limited coverage covered if specific clinical criteria have been met, Not listed not covered unless approved through Individual Clinical Review

${ }^{a}$ Notice of compliance dates provided only for the first available dosing of each agent. We have not included oral bisphosphonate combination therapy

${ }^{\mathrm{b}}$ Available through special authority: clinical or radiographically documented fracture due to osteoporosis or patients who are receiving or expected to receive the equivalent of $7.5 \mathrm{mg}$ /day of prednisone equivalent for 90 consecutive days or longer

${ }^{\mathrm{c}}$ Limited use history, Nov 2000 (alendronate) and Mar 2001 (risedronate): failed ${ }^{\mathrm{g}}$ etidronate therapy or experience intractable side effects with etidronate or documented allergy which precludes continuation with etidronate therapy; Apr 2003 (alendronate/risedronate): above or two of the following three criteria: (1) bone mineral density T-score $<-3.0$, (2) aged 75 or more years, and (3) prior osteoporosis-related fracture

${ }^{\mathrm{d}}$ Available under the exceptional access program: treatment of osteoporosis in persons unable to absorb or take oral products

${ }^{\mathrm{e}}$ Available under the exceptional access program: treatment of osteoporosis in persons who have failed ${ }^{\mathrm{g}}$, experienced intractable side effects to or have contraindication to all of the available Formulary alternatives (oral bisphosphonate and if patient is female raloxifene)

${ }^{\mathrm{f}}$ Available through special authority: clinical or radiographically documented fracture due to osteoporosis or unsatisfactory clinical response, defined as a new fragility fracture after 1 year adherence to alendronate or risedronate

${ }^{\mathrm{g}}$ Failed: continued loss of bone mineral density of more than $3 \%$ after 2 years of therapy, new fracture after 1 year of therapy

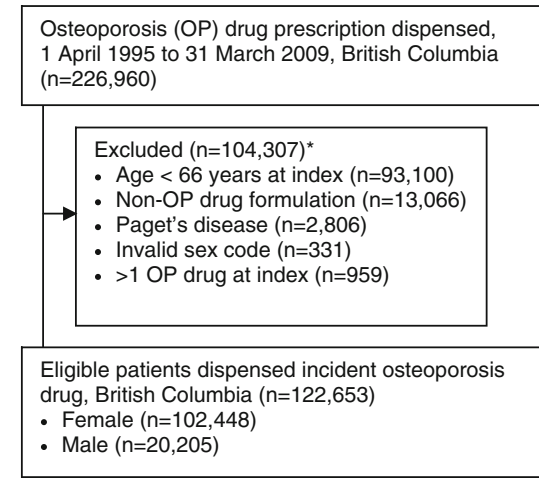

Fig. 1 Study flow diagram. Osteoporosis drugs were bisphosphonates (alendronate, 5, 10, or $70 \mathrm{mg}$; cyclical edidronate; risedronate, 5, 35, 75 , or $150 \mathrm{mg}$; zoledronic acid $5 \mathrm{mg} / 100 \mathrm{ml}$ ); nasal calcitonin (200 U); raloxifene; or teriparatide. Denosumab was approved in 2010 and thus is not included in this study. First date of eligible drug

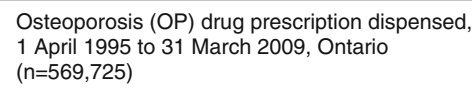

prescription defined entry, participants were permitted to enter the cohort only once and thus the data capture the first prescription for eligible osteoporosis treatment. Asterisk may meet more than one exclusion criterion 
Fig. 2 Number of patients dispensed incident osteoporosis medication from April 1995/ March 1996 to April 2008/ March 2009, by sex (white bar female; gray bar male) and drug type (line graph); residents aged 66 or more years in a British Columbia and b Ontario
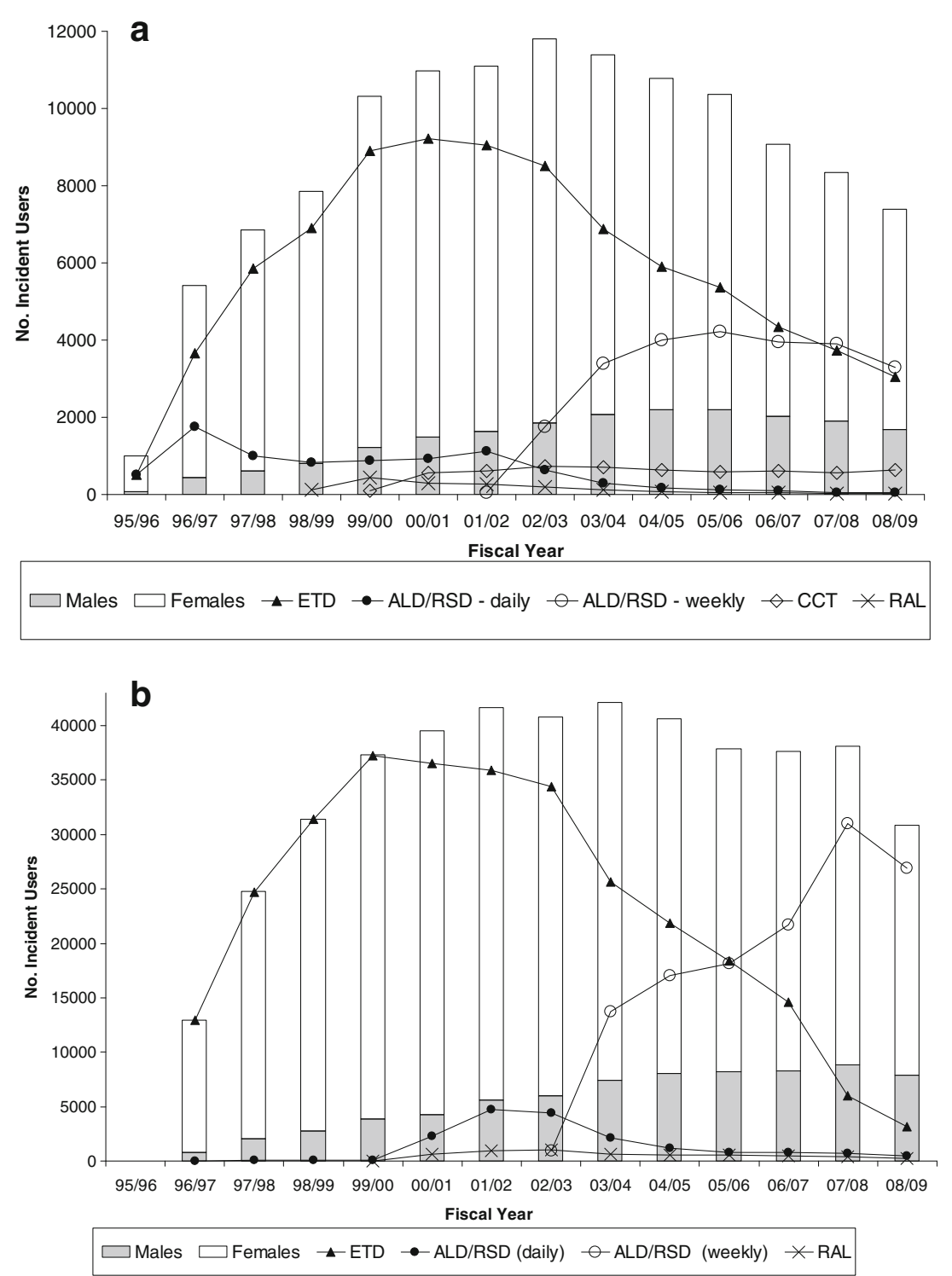

entering the market and changes in listing status on provincial drug formularies. Oral bisphosphonates have dominated treatment and follow evidence-based guidelines [7-9]. Despite drug availability in Canada, differential coverage through provincial public drug plans for seniors has limited access to some agents. In particular, we identify that when not restricted by a public drug plan formulary, physicians prefer to prescribe secondgeneration (alendronate or risedronate) oral bisphosphonates. This is evidenced by drugs dispensed outside $\mathrm{BC}$ PharmaCare and the quick convergence to weekly bisphosphonates once coverage for alendronate and risedronate broadened in Ontario.

Although we document differences in treatment with second-generation bisphosphonates in BC based on public formulary listing status, we cannot claim disparity in access to effective osteoporosis medication. The discrepancy in listing status is related to the price differential between agents, with etidronate being the least expensive. The annual cost before dispensing fees for generic medications paid through the Ontario Drug Benefits Plan is approximately $\$ 80$ for cyclical etidronate and $\$ 130$ for weekly alendronate or risedronate [5]. With a \$50 annual difference, every 20,000 users of alendronate or risedronate instead of etidronate costs the public system \$1 million. The difference in costs between agents may be justifiable if one agent is more effective at reducing fracture risk. However, little comparative effectiveness data are available to support the superiority of any of the oral bisphosphonates in reducing fracture risk. To our knowledge, only a single study has directly compared the effects of etidronate to alendronate or risedronate in reducing fracture risk [10]. Authors found little difference in hip fracture rates within 2 years between female fracture 
Fig. 3 Number of patients dispensed incident osteoporosis medication from April 1995/ March 1996 to April 2008/ March 2009, by sex (white bar female, gray bar male) and drug type (line graph); residents aged 66 or more years in British Columbia a within PharmaCare and $\mathbf{b}$ outside PharmaCare
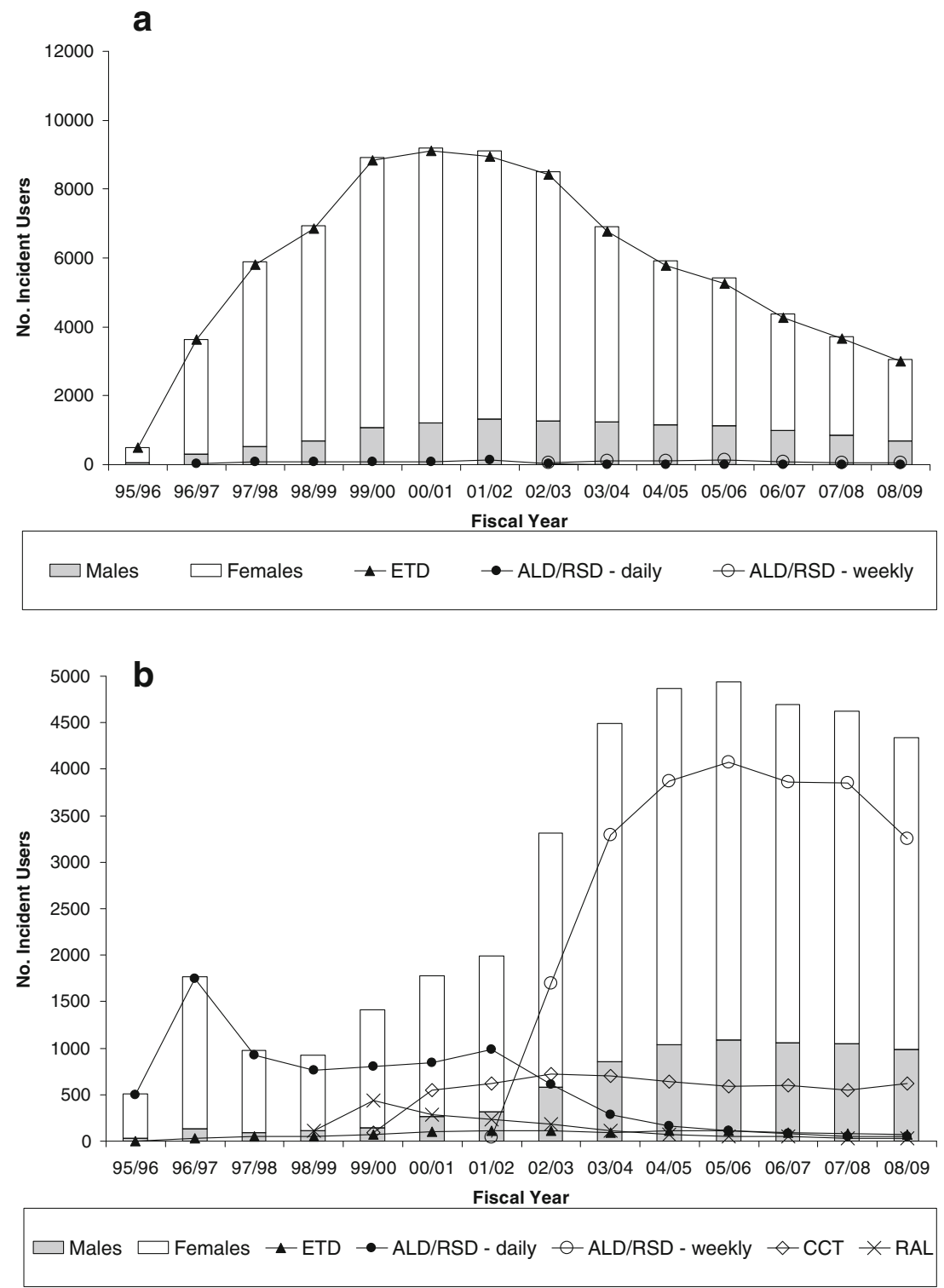

patients receiving etidronate compared to alendronate or risedronate $(\mathrm{HR}=1.0,95 \% ; \mathrm{CI}=0.6-1.6)[10]$. More data are needed to clarify the comparative effectiveness of oral bisphosphonates in reducing fracture risk. Many provinces in Canada continue to restrict access to alendronate and risedronate through public drug plans. In the absence of clear evidence of superiority compared with etidronatedespite differences between agents based on placebocontrolled trials - it may be difficult for policy makers to justify the additional costs to the public healthcare system by covering second-generation bisphosphonates without restriction.

Our study is subject to some limitations. First, we were limited to publicly funded drug claims in Ontario, restricting us from assessing drugs dispensed yet processed through private insurance or out-of-pocket.
Thus, we are limited in ability to assess the use of medications that are not listed on the Ontario formulary such as calcitonin, teriparatide, and zoledronic acid, as well as alendronate and risedronate dispensing outside the public plan. Second, we are limited to pharmacy claims data and do not have a record of medications prescribed yet not dispensed in community pharmacies. Despite these limitations, our study has significant strength. We were able to generate temporal trends in drug dispensing patterns and identify significant differences in osteoporosis pharmacotherapy between provinces in Canada related to drug coverage policies. BC recently broadened coverage for alendronate (November 2009) and risedronate (January 2011) to remove the need for a prior trial of etidronate. However, access to these second-generation bisphosphonates through $\mathrm{BC}$ 
PharmaCare still requires clinical or radiographically confirmed fracture or long-term glucocorticoid use.

Our results identify that physicians prefer to prescribe following evidence-based guidelines that rank treatment as first-line (e.g., alendronate, risedroante) or second-line (e.g., etidronate) based on placebo-controlled efficacy in reducing fracture risk, with a shift toward alendronate and risedronate when available. Better evidence regarding the comparative effectiveness of oral bisphosphonates is needed to inform drug policy decision making in Canada. At this time, it is difficult to claim inequity in access to effective bone-sparing medications in Canada, yet it is interesting to note that differences in public access to guidelinerecommended first-line treatment exist. The implications of differential access to oral bisphosphonates warrants further study.

Acknowledgements This research was supported by research grants from the Canadian Institutes of Health Research (CIHR, DSA-10353) and the Ontario Ministry of Research and Innovation (OMRI, Early Researcher Award). Ms Beak was supported by a CIHR Health Professional Student Research Award, and Drs Cadarette (Aging and Osteoporosis) and Dormuth (Knowledge Translation) hold CIHR New Investigator Awards. Authors acknowledge Brogan Inc. for providing access to drug identification numbers used to identify eligible drugs. The Institute for Clinical Evaluative Sciences (ICES) is a nonprofit research corporation funded by the Ontario Ministry of Health and Long-Term Care. The opinions, results, and conclusions are those of the authors and are independent from the funding sources. No endorsement by CIHR, ICES, OMRI, or the Ontario Ministry of Health and Long-Term Care is intended or should be inferred.

\section{Conflicts of interest None.}

Open Access This article is distributed under the terms of the Creative Commons Attribution Noncommercial License which per- mits any noncommercial use, distribution, and reproduction in any medium, provided the original author(s) and source are credited.

\section{References}

1. Papaioannou A, Morin S, Cheung AM et al (2010) 2010 clinical practice guidelines for the diagnosis and management of osteoporosis in Canada: summary. Can Med Assoc J 182:1864-1873

2. MacLean C, Newberry S, Maglione M et al (2008) Systematic review: comparative effectiveness of treatments to prevent fractures in men and women with low bone density or osteoporosis. Ann Intern Med 148:197-213

3. Cranney A, Guyatt G, Griffith L et al (2002) IX: Summary of meta-analyses of therapies for postmenopausal osteoporosis. Endocr Rev 23:570-578

4. Osteoporosis Canada Provincial Drug Coverage Chart. http:// www.osteoporosis.ca/index.php/ci_id/9046/la_id.htm. Accessed 11 Jan 2011

5. Ontario Ministry of Health and Long-Term Care Formulary Search: Ontario Drug Benefit Formulary/Comparative Drug Index. https://www.healthinfo.moh.gov.on.ca/formulary/index.jsp. Accessed 11 Jan 2011

6. Cadarette SM, Jaglal SB, Raman-Wilms L, Beaton DE, Paterson JM (2011) Osteoporosis quality indicators using healthcare utilization data. Osteoporos Int 22:1335-1342

7. Brown JP, Josse RG, Scientific Advisory Council of the Osteoporosis Society of Canada (2002) 2002 Clinical practice guidelines for the diagnosis and management of osteoporosis in Canada. Can Med Assoc J 167(10 Suppl):S1-S34

8. Brown JP, Fortier M, Frame H et al (2006) Canadian consensus conference on osteoporosis, 2006 update. J Obstet Gynaecol Can 28:S95-S112

9. Scientific Advisory Board, Osteoporosis Society of Canada (1996) Clinical practice guidelines for the diagnosis and management of osteoporosis. Can Med Assoc J 155:1113-1133

10. Mamdani M, Kopp A, Hawker G (2007) Hip fractures in users of first- vs. second-generation bisphosphonates. Osteoporos Int 18:1595-1600

11. Health Canada Notice of compliance (NOC) online query. http:// webprod3.hc-sc.gc.ca/noc-ac/index-eng.jsp. Accessed 12 April 2011 